\title{
Psychophysiological Reactivity in Couples During a Marital Interaction Task
}

\author{
J. Coutinho ${ }^{1}(\mathbb{D})$ P. Oliveira-Silva ${ }^{1,2} \cdot$ A. R. Mesquita ${ }^{1} \cdot$ M. Barbosa $^{1} \cdot$ \\ K. M. Perrone-McGovern ${ }^{3}$ O. F. Gonçalves ${ }^{1,4,5,6}$
}

Published online: 2 September 2017

(C) Springer Science+Business Media, LLC 2017

\begin{abstract}
The ability to regulate our own physiological arousal when dealing with the emotional expression of our partner is crucial for satisfactory and stable intimate relationships. In previous physiological studies of marital interactions, researchers have found greater levels of psychophysiological arousal for members of the couple in conflictual interactions in comparison with positive interactions. Past researchers have established that intense and prolonged autonomic and neuroendocrine arousal during marital conflict can have negative consequences for mental and physical health. In this study we examined the physiological reactivity, as measured by skin conductance level, heart rate and cortisol levels, from both partners during a couple's interaction task consisting of a structured conversation about positive and negative aspects of their relationship.
\end{abstract}

J. Coutinho

joanafpc@gmail.com

1 Neuropsychophysiology Lab, CIPsi, School of Psychology, University of Minho, Campus de Gualtar, 4710-057 Braga, Portugal

2 Human Neurobehavioral Laboratory (HNL), Centre for Studies in Human Development (CEDH), Faculty of Education and Psychology, Universidade Católica Portuguesa (FEP-UCP), Porto, Portugal

3 Department of Counseling Psychology and Guidance Services, Ball State University, Muncie, IN, USA

4 Department of Applied Psychology, Bouvé College of Health Sciences, Northeastern University, Boston, MA, USA

5 Spaulding Center of Neuromodulation, Spaulding Rehabilitation Hospital and Massachusetts General Hospital, Harvard Medical School, Boston, MA, USA

6 Social and Cognitive Neuroscience Laboratory, Mackenzie Presbyterian University, São Paulo, Brazil
Participants were thirty-two heterosexual couples $(N=64)$ in a committed monogamous relationship with a minimum duration of one year. We found higher heart rate and cortisol levels during negative interaction condition when compared with the positive condition. Skin conductance was higher in the positive interaction condition, when compared with the negative interaction condition. In addition, we found a significant negative association between heart rate variability and autonomic arousal evoked by the interaction task. The implications of these findings for the effects of marital strain on health as well as for the design of risk-reducing interventions, namely biofeedback are discussed.

Keywords Couples $\cdot$ Marital interaction $\cdot$ Physiological measures $\cdot$ Skin conductance $\cdot$ Heart rate $\cdot$ Cortisol

\section{Introduction}

Romantic relationships constitute the most central relationship for most adults and have an important temporal duration in the human life cycle (Robles and Kiecolt-Glaser 2003). Empirical research has shown that relationship satisfaction is associated with partners' psychological adjustment and better health, whereas marital conflict leads often to social and health problems (Bookwala 2005; Kiecolt-Glaser and Newton 2001; Lehnart et al. 2010). The consequences of marital conflict and divorce for society are relevant considering the impact of negative affect for the physical and mental health of each partner (SunWoo and Marks 2016; Umberson et al. 2006), as well as for those directly involved in marital conflict such as children (El-Sheikh et al. 2009).

Seminal research on couples has demonstrated that the presence of reciprocal negative affect during couples' conflict resolution predicts decreases in marital satisfaction over 
a 3-year (Levenson and Gottman 1985) and 5-year period (Markman 1981). Moreover, negative affect, and the associated heightened levels of physiological arousal, has deleterious health consequences, such as: increased cardiovascular reactivity and neuroendocrine stress response (Robles and Kiecolt-Glaser 2003; Rodriguez and Margolin 2013). For example, in terms of cardiac activity, there is evidence that high levels of marital conflict or strain are related with increased risk of cardiovascular disorder and poor prognosis among persons with heart disease (Coyne et al. 2001; Gallo et al. 2003; Matthews and Gump 2002; Orth-Gomer et al. 2000).

The main aim of this study is to investigate the physiological reactivity of both members of romantic couples during negative interactions, when compared with positive interactions. Previous evidence suggests that negative affect produces widespread physiological activation. Part of this physiological response results from the activation of the sympathetic branch of the autonomic nervous system (ANS), leading to increases in blood flow in skeletal muscles as well as increased cardiac rate, sweating, and respiration (Levenson 2003; Robles and Kiecolt-Glaser 2003). The physiological response also derives from the activation of the Hypothalamic-pituitary-adrenal (HPA) axis resulting in increased levels of adrenocortical hormones such as cortisol (Erickson et al. 2003; Rodriguez and Margolin 2013; Schwabe et al. 2008).

An empirical review of experimental studies reporting the effects of emotion on ANS activity (Kreibig 2010) suggested that specific negative emotions (anger, threat, fear or disgust) might be associated with different patterns of ANS responsiveness (Ekman et al. 1983). However based on the studies reviewed in this work, Kreibig (2010) asserted that not only the emotional valence (i.e., negative vs. positive), but also the level of intensity (i.e., arousal) plays a role in the peripheral physiological responding.

Previous researchers have found that aversive interpersonal interactions (i.e., marital conflicts) lead to an higher increase over baseline in psychophysiological responses such as heart rate, blood pressure, cortisol and catecholamine release (Robles and Kiecolt-Glaser 2003; Robles et al. 2006; Rodriguez and Margolin 2013; Smith et al. 2006). These changes were shown to be associated with the presence of hostile behavior during marital conflict as well as with couples' reports of marital strain (Kiecolt-Glaser et al. 1997; Newton and Sanford 2003). Similarly, Nealey-Moore et al. (2007) carried out a marital interaction study with 114 couples and found that, compared to positive and neutral conditions, negative discussions evoked higher increases in HR for both men and women.

Most of the research conducted so far with couples measured single autonomic variables. However rather than analyzing single autonomic measures, it is recommended to study patterns of autonomic responding and thus analyze comprehensive arrays of physiological measures (Stemmler 2003). Moreover this multi-measure assessment should consider not only unspecific effects of emotional tasks (which is normally assessed though the comparison between control and emotional conditions), but also specific effects (by comparing negative versus positive interaction conditions). Again to our knowledge few studies with couples have compared different measures of physiological responding in different types of interactions. Our study was specifically designed to address this gap in the literature.

Thus the first objective of this study is to compare the level of physiological arousal, as measured by heart rate, skin conductance level and cortisol level, during a negative marital interaction period and a positive marital interaction period. Due to the known relationship between negative affect and physiological arousal, and considering that both the SNS and the HPA axis are associated with heightened arousal and stress responding (Hugdahl 1995), we expect a higher physiological arousal, as measured by heart rate, EDA and cortisol during the negative marital interaction period when compared with the positive interaction period. The second objective of our study is to examine the relationship between parasympathetic regulation, as measured by heart rate variability (HRV) and autonomic arousal (as measured by the increase in HR, SCL and cortisol levels from baseline to the interaction task). According to the Polyvagal Theory (Porges 2007, 2009), empathic and prosocial behaviors became possible through the arising of the myelinated vagus nerve in the mammalian autonomic nervous system, which plays a major role in the regulation of HRV. Due to its inhibitory effect on the sympathetic system, the vagal tone has been shown to be important for the physiological and emotional regulation and human prosocial behavior (Appelhans and Luecken 2006; Porges 2009). Indeed several studies have linked autonomic flexibility, as indexed by vagal tone, to adequate emotional responding (Appelhans and Luecken 2006) social regulation and connectedness (e.g., Kok and Fredrikson 2010). Therefore in our second research hypothesis we expect that parasympathetic regulation, as measured by the HRV, will be negatively associated with the increase in autonomic arousal (as measured by the increase in HR, electrodermal activity and cortisol levels from baseline to the interaction task).

As a measure of the HRV, we used a frequency-domain measure which is the high-frequency (HF-HRV) component, defined from 0.15 to $0.4 \mathrm{~Hz}$, due to its primary relationship with the parasympathetic branch of the ANS (Berntson et al. 2007; Thayer et al. 2012; Thayer and Lane 2000), since the HF-HRV relates to cardiac vagal control and predicts individual differences in the regulation of the sympathetic activation. The HF-HRV component was calculated through the frequency domain approach, which using power spectral 
density analysis decomposes the total variability into frequency components (Billman 2011). In comparison with the time domain approach, the frequency domain approach has been identified as more useful in identifying specific components of the HRV and seems to provide more detailed information of the cardiac variability (Costa et al. 2017).

By providing a comprehensive assessment of the physiological reactivity of couples in interactive conditions of different valence, this study will have important contributions for the understanding of couple's functioning from both a psychological and physical point of view. Specifically if we are able to demonstrate a dissociation between the psychophysiological responding in negative versus positive interaction like we expect to find, these will help us understand couple's difficulties in managing relational conflict as well as the increased risk for health problems known to be associated with marital problems.

\section{Method}

\section{Participants}

Participants were 32 heterosexual couples $(N=64$ individuals). Couples included in the present study reported being in a committed monogamous romantic relationship for at least 1 year. Participants' ages ranged from 22 to 62 years old $(M=32.32, S D=7.62$; for men: $M=33.33, S D=8.00$; for women: $M=31.30, S D=7.21$ ). Exclusion criteria were as follows: presence of cardiac disease or implant; substance abuse disorders; medication affecting cardiac activity or endocrine function (e.g. beta blockers); presence of physical or mental condition that might affect the physiological measurements; and/or age below 20 years. Of the couples that participated in the present study, 35.7\% were married, 35.7\% were living together and $28.6 \%$ were in dating relationships. Additionally, $40 \%$ of the couples had children. The mean duration of romantic relationships for couples in the present study was 9.4 years $(S D=8.05$; range $1-38$ years). All participants were Caucasian and the majority of participants had college degrees (68\%). The socio-demographic description of the sample is summarized in Table 1.

\section{Self-report Measures}

Self-reported measures of empathy, dyadic empathy and dyadic adjustment were administered to the participants before the experiment. These measures were used for descriptive purposes to help characterize the sample in terms of marital functioning. The scores of these questionnaires are presented in Table 2 and their main psychometric properties are described below.
Table 1 Participant demographics

\begin{tabular}{lll}
\hline Age & $M=32.3(S D=7.7)$ & Min $=22$, max $=62$ \\
Educational level & $\begin{array}{l}\text { College education or } \\
\text { greater }\end{array}$ & $68 \%$ \\
& 12th grade & $22 \%$ \\
& 9th grade & $7 \%$ \\
& Basic education & $3 \%$ \\
Marital status & Married & $35.7 \%$ \\
& Living together & $35.7 \%$ \\
Relationship duration & Dating & $28.6 \%$ \\
With children? & Yes & Min $=1, \max =38$ \\
& No & 12 \\
& & 20 \\
\hline
\end{tabular}

Table 2 Descriptive statistics of the self-report measures

\begin{tabular}{llll}
\hline & \multicolumn{3}{l}{ Participants } \\
\cline { 2 - 4 } & Male M (SD) & Female M (SD) & All M (SD) \\
\hline IRI & & & \\
PT & $14.81(2.39)$ & $16.63(2.98)$ & $15.72(2.83)$ \\
EC & $13.65(2.86)$ & $14.1(3.3)$ & $13.87(3.07)$ \\
PD & $11.77(3.21)$ & $12.52(2.99)$ & $12.15(3.1)$ \\
FS & $10.35(3.4)$ & $12.23(3.05)$ & $11.29(3.34)$ \\
Total & $50.58(6.88)$ & $55.47(8.27)$ & $53.03(7.94)$ \\
IRIC & & & \\
PT & $16.35(3.42)$ & $16(4)$ & $16.18(3.7)$ \\
EC & $23.45(2.77)$ & $23.81(3.67)$ & $23.63(3.23)$ \\
Total & $39.81(4.45)$ & $39.9(5.18)$ & $39.85(4.79)$ \\
DAS & & & \\
Consensus & $24.29(2.95)$ & $24.55(2)$ & $24.42(2.5)$ \\
Satisfaction & $15.81(2.04)$ & $15.48(1.73)$ & $15.65(1.88)$ \\
Cohesion & $12.77(4.23)$ & $13.13(3.88)$ & $12.95(4.03)$ \\
Total & $52.87(6.99)$ & $53.16(5.31)$ & $53.02(6.16)$ \\
\hline
\end{tabular}

Mean (M) and standard deviations (SD) of the questionnaire scores (IRI Interpersonal Reactivity Index, $P T$ perspective-taking scale, $F S$ fantasy scale, $E C$ empathic concern scale, $P D$ personal distress scale, IRIC Interpersonal Reactivity Index for Couples, DAS Dyadic Adjustment Scale)

Interpersonal Reactivity Index (IRI; Davis 1980; Portuguese version, Limpo et al. 2010). IRI is a 28 -item measure of general empathic tendencies that assesses both cognitive and emotional components of empathy. Items are scored on a five-point Likert scale. IRI yields four subscales each one with seven items: perspective taking, empathic concern, fantasy and personal distress. Higher scores in the IRI indicate higher levels of self-perceived empathic ability. Items in each subscale are summed to obtain the subscale score (score range for each scale $=0-28$ ), and a high score means higher fantasy, perspective taking, empathic concern, and personal distress, respectively. The Portuguese version of the scale has adequate values of validity and internal consistency 
( $\alpha=0.73$ for perspective taking subscale; $\alpha=0.76$ for empathic concern subscale; $\alpha=0.80$ for personal distress and $\alpha=0.84$ for fantasy).

Interpersonal Reactivity Index for Couples (IRIC; Péloquin and LaFountaine 2010; Portuguese version, Coutinho et al. 2015)-IRIC is a modified version of the IRI that assesses cognitive and emotional empathy in the context of intimate relationships with 13 items evaluated on a fivepoint Likert scale yielding two subscales. The dyadic perspective taking subscale composed by six items measures the tendency to spontaneously adopt the partner's points of view. The dyadic empathic concern subscale composed by seven items focuses on feelings of sympathy and concerns oriented towards the partner in unfortunate situations. The IRIC total score can vary between 0 and 52, with a higher score indicating higher perceived empathy within the couple's relationship. The score of dyadic perspective taking can vary between 0 and 24 and the score of dyadic empathic concern can vary between 0 and 28 . The Portuguese version of IRIC has good internal reliability ( $\alpha=0.85$ for perspective taking subscale; $\alpha=0.67$ for empathic concern subscale).

Dyadic Adjustment Scale-Revised (R-DAS; Spanier 1976; revised version by Busby et al. 1995; Portuguese version of R-DAS: Pereira 2003)—R-DAS assesses each partner's perceived degree of marital adjustment. R-DAS is composed of 14 items, integrated in three sub-scales: consensus, satisfaction and cohesion. The total score can range between 0 and 69 , with a higher score indicating better adjustment. The Portuguese version of R-DAS has good internal reliability, both for the global scale $(\alpha=0.84)$ and its three sub-scales (consensus: $\alpha=0.81$; satisfaction: $\alpha=0.81$; cohesion: $\alpha=0.79$ ).

\section{Procedures}

The local Institutional Review Board approved this study and all participants provided informed written consent.
Participants were recruited through informal advertisement, using a snowball sampling approach. Information about the study was also provided on the Facebook page of our laboratory. Once the local IRB does not allow the offer of monetary compensation for the participation in research, the couples received a voucher from a book store for their participation in the study. Prior to any experimental procedure, all couples were screened on the telephone concerning the inclusion criteria. Participants were instructed to abstain from alcohol, nicotine, and caffeine for at least $4 \mathrm{~h}$ prior to data collection. On arrival, couples were provided with an overview of the procedures. They were told that the main goal of this study was to look at the relationship between physiological arousal and couple's interaction. Prior to the experiment they were also given basic information about the psychophysiological devices including the BIOPAC equipment and the disposables for saliva collection. Before the physiological data collection participants completed, individually, a sociodemographic questionnaire and selfreport measures of empathy. Then they were asked to sit in a comfortable position, each one on a different sofa, so that they were able to easily look directly at each other and to interact with one another as naturally as possible. Before the placement of the electrodes, the skin was cleaned with alcohol and dried with cotton to diminish the impedance and to improve the quality of the electrophysiological signal. One researcher acted as a mediator during the couple's interaction to ensure that both partners closely followed the instructions described below. The physiological measures were continuously recorded during the baseline task and during the couple's interaction task (Fig. 1).

\section{Psychophysiological Assessment}

Physiological recordings were performed continuously during the baseline and interaction task at a sampling rate of $1000 \mathrm{~Hz}$ for both HR and SCL channels. The modules

Fig. 1 Schematic representation of the experimental task

Couple's Interaction task

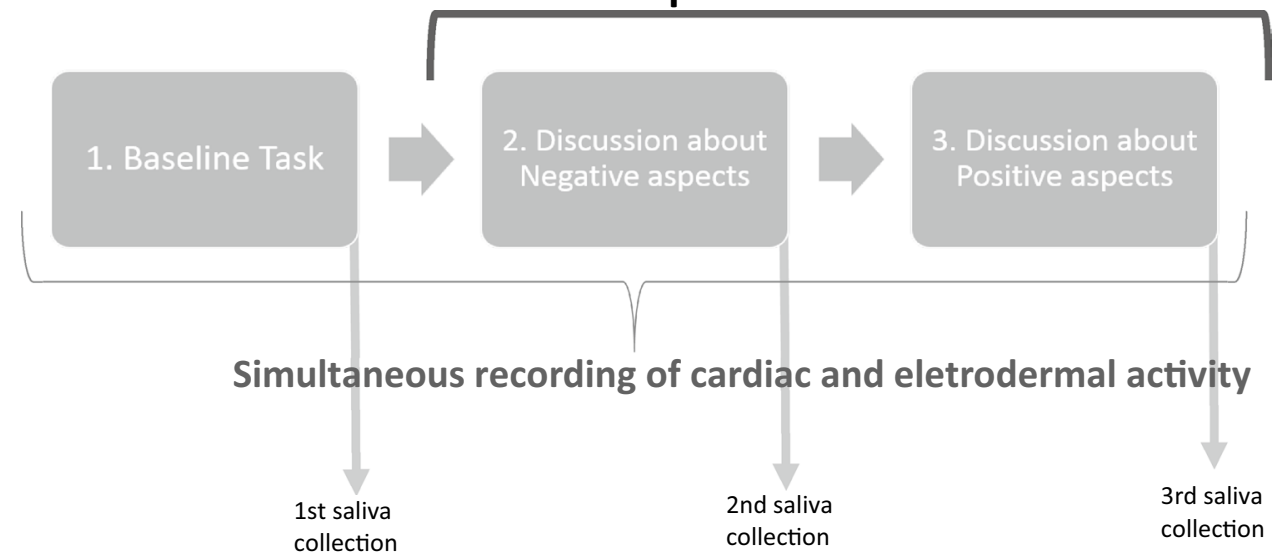


BN-PPGED and BN-RSPEC of the Biopac BioNomadix wireless acquisition device (Biopac Systems; Santa Barbara, CA) were used for the recording of the cardiac and electrodermal activities, respectively. The acquisition device was connected to a host computer running AcqKnowledge software (version 4.4). In general, the quality of the recorded data was high, with very little interference due to movement. The following variables were calculated: (1) a single mean score for each period of interest, in order to compare the intra-individual differences in the physiological arousal between the negative and positive interaction periods; (2) change scores, one from the baseline to negative period, and other from the baseline to positive period, which accounts for proportion of change, in order to determine the relationship between the parasympathetic regulation and the autonomic arousal; and, only for the cardiac data, (3) the HF-HRV component, extracted from the baseline period by the frequency-domain analysis of HRV algorithm in the Acknowledge software, which represents the parasympathetic regulation index.

\section{Skin Conductance Level}

Skin conductance level (SCL) is one of the measures of the electrodermal activity (Cacioppo et al. 2007). Participants' skin conductance (in siemens) was measured using a pair of pre-gelled disposable electrodes with a circular contact area of $1 \mathrm{~cm}$ diameter and isotonic gel (EL-507, Biopac Systems, Santa Barbara, CA) attached to the palmar surface of the medial phalanges of the index and middle fingers of the nondominant hand. The raw SCL data were filtered using the recommended standard filter settings for the acquisition device, a FIR low-pass Blackman filter of $1 \mathrm{~Hz}$ with the number of coefficients set at 4000 . For the data reduction, the recordings were examined visually for remaining artifacts, but none were found. Subsequently, the within-subjects means were calculated based on 1-s epochs within each period of interest, and finally, exported to SPSS for further analysis. The mean values for SCL during the baseline, negative and positive condition can be seen in Fig. 2 and Table 3.

\section{Cardiac Measures}

The raw Electrocardiogram (ECG) was used to measure the participants' HR (measured in beats per minute or bpm) using an adjusted 3-electrode Lead-II configuration. The nonpolarizable disposable $\mathrm{Ag}-\mathrm{AgCl}$ electrodes were placed on the participants' right and left mid-clavicle, and a third one on the top of the left shoulder. The raw ECG data were filtered using the recommended standard filter settings for the acquisition device, an IIR high-pass filter of $1 \mathrm{~Hz}$ and an IIR low-pass filter set at $35 \mathrm{~Hz}$. For the data reduction,

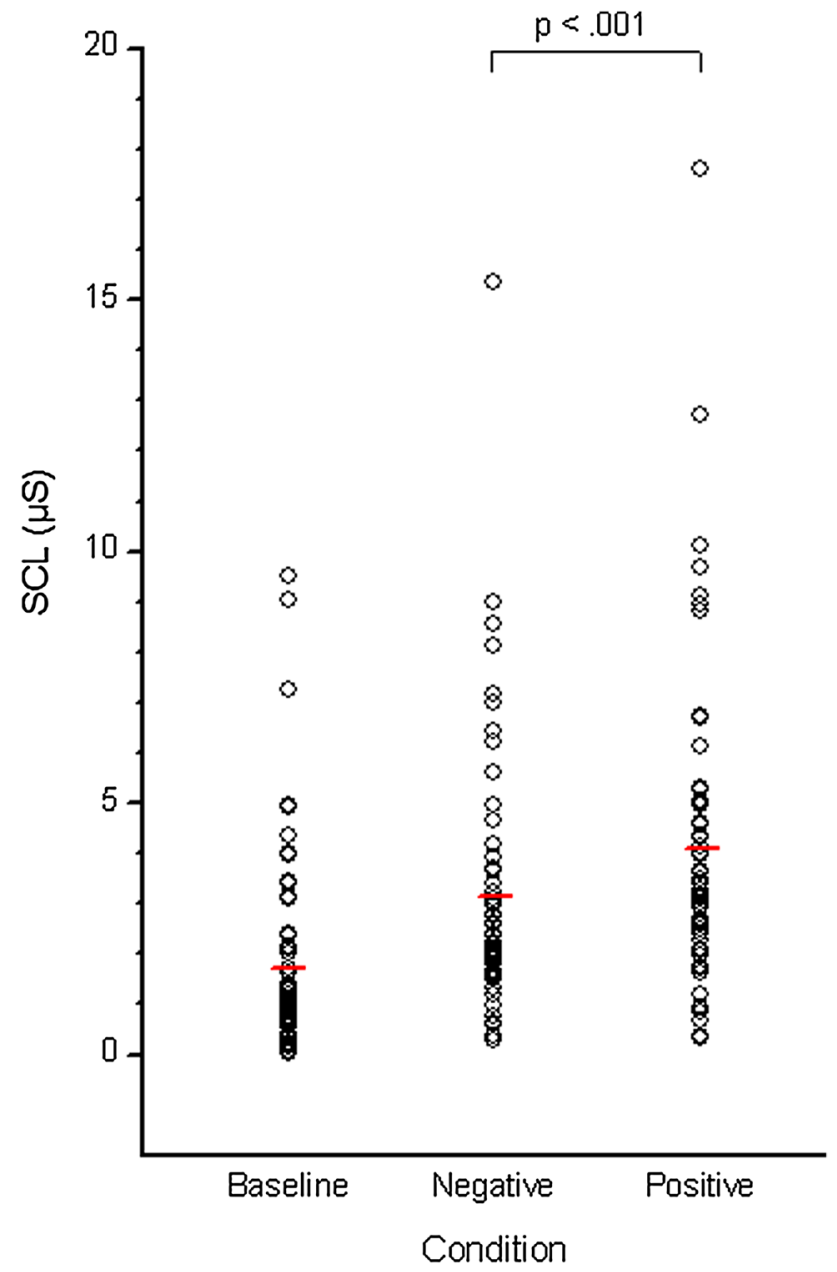

Fig. 2 Estimated means of electrodermal activity in the three conditions (baseline, negative and positive interaction)

Table 3 Descriptive statistics of the physiological measures

\begin{tabular}{|c|c|c|c|}
\hline & \multicolumn{3}{|l|}{ Participants } \\
\hline & Male M (SD) & Female $\mathrm{M}(\mathrm{SD})$ & All M (SD) \\
\hline \multicolumn{4}{|l|}{ Cortisol } \\
\hline Baseline & $0.48(0.38)$ & $0.37(0.33)$ & $0.43(0.35)$ \\
\hline Negative & $0.50(0.37)$ & $0.36(0.41)$ & $0.43(0.39)$ \\
\hline Positive & $0.36(0.25)$ & $0.30(0.27)$ & $0.33(0.26)$ \\
\hline \multicolumn{4}{|l|}{ HR } \\
\hline Baseline & 80.57 (12.44) & $84.11(9.43)$ & 82.34 (11.09) \\
\hline Negative & $80.76(11.28)$ & $84.67(8.90)$ & $82.71(10.27)$ \\
\hline Positive & 78.79 (10.16) & $82.99(7.61)$ & $80.89(9.15)$ \\
\hline \multicolumn{4}{|l|}{ SCL } \\
\hline Baseline & $1.76(2.26)$ & $1.7(1.72)$ & $1.73(1.99)$ \\
\hline Negative & $3.35(3.04)$ & $2.95(2.06)$ & $3.15(2.58)$ \\
\hline Positive & $4.54(3.63)$ & $3.67(2.23)$ & $4.11(3.02)$ \\
\hline
\end{tabular}

Mean (M) and standard deviations (SD) for SCL skin conductance level $(\mu \mathrm{S}), H R$ heart rate $(\mathrm{bpm})$ and cortisol $(\mu \mathrm{g} / \mathrm{dl})$ during the baseline, negative and positive interactions 
the recordings were examined visually for ectopic beats and remaining artifacts. Heart rate and the HF-HRV were calculated offline from the filtered ECG trace using the Acknowledge software (AcqK). As previously mentioned to measure HRV we used a frequency domain approach that allows for the partition of the total variability into frequency components, thus allowing the identification of specific components of heart rate variability. The band-limited variance for the HF-HRV index was extracted through the automated analysis tool provided by the manufacturer which uses as a spectral analysis approach the Fast Fourier Transformation analysis (FFT) method, according to the international cardiology standards (Camm et al. 1996; Trimmel et al. 2015). Thus, the within-subjects means were calculated based on 1-second epochs within each period of interest for the HR measure. The data were exported to SPSS for further analysis. Mean values for HR during the baseline, negative and positive periods can be seen in Fig. 3 and Table 3.

\section{Neuroendocrine Measures-Cortisol}

Saliva samples were obtained by using the standard sampling device—salivette (Sarstedt, Nümbrecht, Germany). Participants were instructed to chew a roll of cotton until it was saturated (approximately 1 min duration) and then to place it inside a retainer in a centrifuge tube. In order to minimize potential contamination, participants were told not to eat within $30 \mathrm{~min}$ prior to sample collection. Upon arrival at the laboratory (after informed written consent was obtained), participants were asked to collect the first saliva sample for baseline assessment of cortisol levels. In order to assess cortisol response to both negative and positive marital interaction, a second and a third sample of saliva were collected immediately after each episode, respectively. All saliva samples were kept on ice during the experimental procedure, and were centrifuged and stored in a freezer at $-20{ }^{\circ} \mathrm{C}$ immediately after the procedure. Cortisol determination was performed according to the manufacturer's instructions using the commercially available IBL Kit for Cortisol Saliva ELISA (IBL, Hamburg, Germany). The assay has a lower detection limit of $0.005 \mathrm{ug} / \mathrm{dl}$ with intra- and interassay coefficients of variations $<9 \%$. Mean values for cortisol during the baseline, negative and positive periods can be seen in Fig. 4 and Table 3.

\section{Baseline Task}

The baseline task was designed to provide referential values of heart rate and skin conductance for each participant. As recommended by Jennings et al. (1992), the baseline task was a simple and undemanding task in which participants were presented and asked to briefly describe a set of 16 neutral valence and low-arousal pictures selected from the

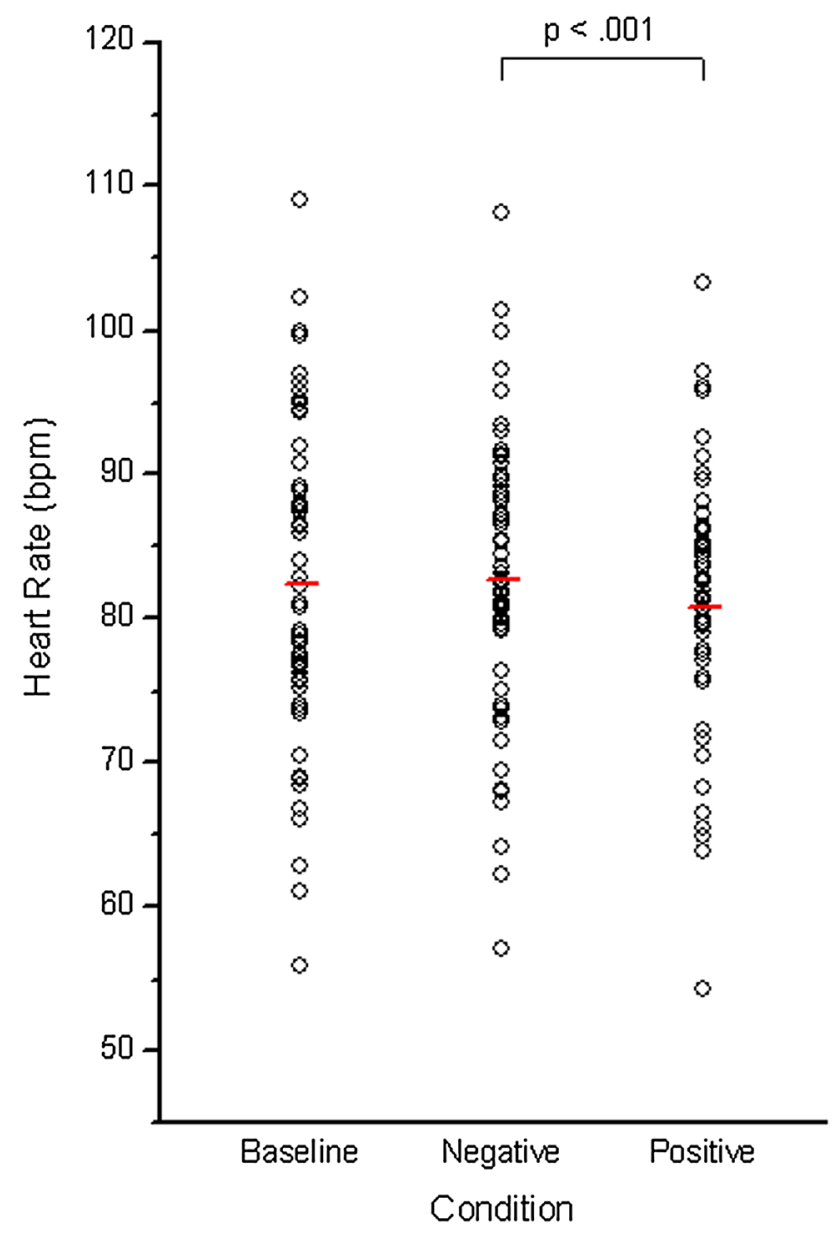

Fig. 3 Estimated means of heart rate in the three conditions (baseline, negative and positive interaction)

International Affective Picture System (IAPS—Lang et al. 2008). Pictures were presented in a laptop, using Presentation software (Microsoft Office ${ }^{\circledR}$ PowerPoint). A fixation cross was presented between pictures in the center of screen during $5 \mathrm{~s}$. Physiological measures from the baseline period were averaged to establish individual baseline values for both HR and SCL.

\section{Couples Interaction Task}

When selecting the interaction task for this experiment we considered both ecological and internal validity issues. Thus we selected a task that is inspired in couple's therapy (Christensen et al. 2004) resembling couples' natural interactions, allowing at the same time its adaptation to a laboratory based setting.

The task consisted in a structured discussion about the negative and positive aspects of their relationship (Fig. 1). Participants were instructed to start talking about the negative aspects, which was then followed by a discussion of the 


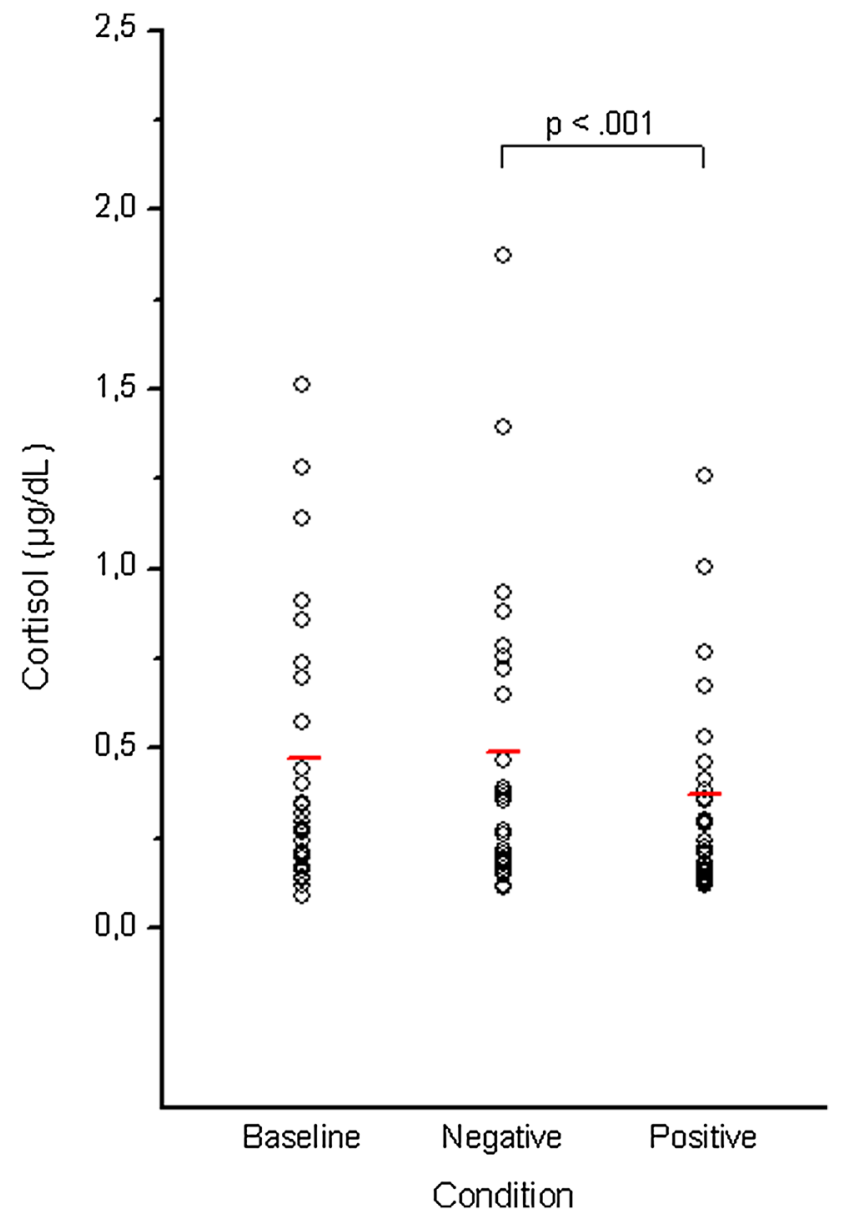

Fig. 4 Estimated means of cortisol in the three conditions (baseline, negative and positive interaction)

positive aspects. This option was based on ethical considerations and methodological options of other studies of marital interaction (e.g., Perrone-McGovern et al. 2014). Each partner was instructed to focus on a single negative aspect or problem at a time and elaborate it with all possible detail. The other partner should not argue or answer back. Partners switched their roles up until they covered all the important topics. An example of the specific instructions given to the participant for the negative aspects were as follows: You will have two minutes to talk to your partner about one negative aspect of your relationship (e.g. things that make you feel upset; things that you would like to change; things that bother you in your relationship; things you don't like about your partner). You should use this time to talk with enough detail about each topic, by giving specific examples or by talking about the negative impact that this has on you. You should talk about one topic at a time, i. e., you should not talk about money issues and problems related with time management in the same period of $2 \mathrm{~min}$. The same procedures and the same instructions were applied to the discussion of the positive aspects. These were described as things that make you feel happy; things you would like to keep as it is, things you admire about your partner. On average each phase (positive and negative) lasted for about $20 \mathrm{~min}$, with a total duration for the interaction task of about $40 \mathrm{~min}$.

\section{Statistical Analyses}

Data analysis was performed using IBM $^{\circledR}$ SPSS $^{\circledR}$ version 22.0 statistical software. An exploratory analysis was performed to test the assumptions underlying the use of parametric tests. Both the assumptions of normality ( $\mathrm{Kol}$ mogorov-Smirnov, $p>.05$; Shapiro-Wilk, $p>.05)$ and homogeneity of variances (Levene Statistic, $p>.05$ ) were fulfilled.

In order to test for differences in the physiological arousal between conditions a two-way mixed ANOVA was performed with valence of the interaction (positive vs. negative) as a within subject factor and sex (female vs. male) as a between subject factor. When a significant main effect or interaction was found, posthoc t-tests were performed with significance set at $p<.05$ (two-tailed) to compare mean differences.

Finally we used Pearson's correlation test to analyze the relationship between HRV vagal index (HF-HRV) and autonomic arousal (measured by the increase in SCL, HR and cortisol from the baseline to the interaction task). The level of statistical significance was kept at $p<.05$ for all the analyses.

\section{Results}

\section{Effect of Valence of Marital Interaction Task in Autonomic Reactivity}

\section{Cardiac Activity}

A two-way mixed ANOVA revealed a significant main effect of the valence of interaction in cardiac reactivity as measured by HR, $F(1,56)=3.87, p=.02$. Post-hoc pairwise comparisons with Bonferroni correction revealed that participants presented significantly greater HR in the negative condition $(M=82.72, S D=10.27)$, than in the positive condition $(M=80.89, S D=9.16)(p=.001)$. No significant main effect for $\operatorname{sex}[F(1,58)=2.449, p>.05]$, nor for the interaction between the valence and the sex was found $[F(2$, $36)=80.43, p>.05]$ (Fig. 3).

\section{Neuroendocrine Measure}

We found a significant main effect for the valence of the interaction in cortisol levels, $[F(1,29)=4.43, p=.01]$. Post-hoc pairwise comparisons with Bonferroni correction 
revealed that participants demonstrated significantly greater cortisol levels immediately after the negative interaction $(M=0.39, S D=0.35)$, than after the positive interaction $(M=0.31, S D=0.24), p=.001$. No significant main effect for $\operatorname{sex}[F(1,29)=2.31, p>.05]$, nor for the interaction between the valence and the sex were found $[F(2$, 36) $=0.58, p>.05$ ] (Fig. 4).

\section{Skin Conductance Level}

A significant main effect was found for task valence in SCL $[F(1,56)=18, p=.002]$.. Post-hoc pairwise comparisons with Bonferroni correction revealed that participants demonstrated significantly greater SCL in the positive interaction $(M=4.10, S D=3.02)$, than in the negative interaction $(M=3.15, S D=2.58), p=.001$ (Fig. 2). No significant main effect for sex $[F(1,58)=1.13, p>.05]$, nor for the interaction between the valence and the sex were found $[F(2$, $36)=2.59, p>.05]$.

\section{Association Between HRV and Autonomic Arousal}

We found a significant negative correlation between HRV and the change in SCL $(r=-0.24, p=.04)$ and HR $(\mathrm{r}=-0.32, p=.01)$ from baseline to the negative condition. This change in SCL and HR was computed by subtracting the value during the task minus the baseline value for each individual.

\section{Discussion}

This study aimed at investigating the psychophysiological reactivity of romantic partners during a laboratory-based couple's interaction task. Specifically, we wanted to compare electrodermal, cardiac and neuroendocrine activity during negative interactions versus positive interactions. Due to the known relationship between negative emotionality and physiological arousal we expected to find higher levels in our three measures during the negative interaction condition in comparison with the positive interaction condition.

Our results partially confirmed our hypothesis in that we found that participants presented higher levels of physiological arousal (heart rate and cortisol levels) during the negative interactive condition, when compared with the positive interactive condition. Regarding electrodermal activity, we found that couples presented higher levels in the positive interaction condition, when compared with the negative interaction condition.

The increased values of HR and cortisol during the negative condition are consistent with previous physiological studies of couple interactions (e.g., Nealey-Moore et al. 2007; Kiecolt-Glaser and Newton 2001; Rodriguez and
Margolin 2013) that report higher levels of psychophysiological arousal during negative interactions, when compared with positive interactions. This pattern has been associated with a perception of challenge or threat associated with the discussion of negative aspects of the relationships (Feinberg et al. 2013; Tomaka et al. 1993). According to the Polyvagal Theory (Porges 2007), the perception of a threatening environment leads to cardiac acceleration, through an increase in sympathetic activity and a withdrawal in vagal tonus. In fact, in comparison with positive emotions, negative emotions have been associated with stronger ANS responses (Cacioppo et al. 2000).

The same applies to neuroendocrine variables such as catecholamines and cortisol, with greater changes in cortisol during negative interactions in comparison to cortisol changes observed in neutral couple interactions (e.g. Feinberg et al. 2013; Rodriguez and Margolin 2013). Moreover, and most important from a clinical point of view, the increase in autonomic and neuroendocrine measures has been consistently and positively correlated with negative affect and hostile behavior during conflict along with reports of marital strain (Broadwell and Light 1999; Kiecolt-Glaser et al. 1997; Mayne et al. 1997; Newton and Sanford 2003).

Interestingly, classical studies in marital physiology (Notarius and Levenson 1979; Weinberger et al. 1979) have linked the physiological activation in conflict situations to a process described as stonewalling. Stonewalling was first defined by Gottman (1994) as a deteriorated relationship process where partners are withdrawn from relationship interactions and have created a "stonewall" to keep their partners from affecting them. They may get quiet, refuse to interact or refuse to discuss certain topics or feelings, stop making eye contact, cross their arms or leave the room because they feel hurt, angry or frustrated. This pattern of non-verbal nonexpressivity, repression and denial is likely to be associated with the higher autonomic activation in response to stressfful situations. Considering our data showing the increased levels of cortisol and heart rate during negative interactions, we may speculate that partners may withdraw from negative interaction because they tend to be more physiologically overwhelmed in this type of interaction. In this sense stonewalling may constitute a strategy found by the spouses to escape from conflict and calming themselves down during a stressful situation. The fact that cardiac activity which is under the control of both the sympathetic and parasympathetic branches of the autonomic nervous system (Cacioppo et al. 2007) was higher during the negative interaction, also provides some support for the possibility that "stonewalling" constitutes a freeze response that relates to parasympathetic activation.

Among the three physiological measures analyzed, the SCL was the only one that was higher in the positive condition. That is, along with HR and cortisol, SCL increased 
from baseline to the negative interaction condition. However, differently from HR and cortisol, SCL also increased from the negative to the positive condition. This was an unexpected result. A possible explanation for this result may be related to the fact that SCL tends to be arousal rather than emotional specific. Indeed, other authors have claimed that heart rate is more sensitive to the valence of affective pictures (Greenwald et al. 1989; Lang et al. 1993), whereas SCL seems to be more responsive to the level of arousal of affective pictures independently of its emotional valence (Cuthbert et al. 2000). In the same direction are the results found by Carvalho et al. (2012) in a study measuring SCL and HR in response to emotional movies of different valence and arousal. The authors found that film clips eliciting higher levels of arousal (horror and erotic movies), had increased SCL and decreased HR, when compared with low arousing movies (social negative or positive or objects movies). The authors suggested that differences in SCL and cardiac measures could be due to the fact that negative stimuli have induced a larger activation of the defensive motivational system whereas the positive stimuli induced the appetitive motivational system. The role of physiological arousability of a given stimulus for electrodermal system was also supported by other studies reporting that highly arousing films (Codispoti et al. 2008) and pictures (Bradley et al. 2001; Sánchez-Navarro et al. 2006) induce a HR deceleration and increase in SCL.

Based on the empirical evidence showing that this response pattern of decreased HR and increased SCL seems to reflect a response of orienting and sustained attention to highly arousing stimulus with significant affective intensity (Andreassi 2007; Cacioppo et al. 2007), we may speculate that the higher SCL values on the positive interaction condition found in our study, can be explained by a stronger emotional engagement of the spouses, maybe attributed to the fact observed by us that the participants were less defensive when speaking about the positive aspects of their relationship.

Regarding our second research goal, we found a significant negative association between HRV and the difference in SCL, HR and cortisol values from baseline to the negative interaction condition. In other words, higher HRV, which is an index of parasympathetic regulation, was related with a lower increase in autonomic and neuroendocrine arousal from baseline to the interaction task. This is an important finding, considering that HRV has been consistently related with the regulation of physiological reactivity and emotional regulation through the activity of the parasympathetic branch of the ANS system. Indeed the capacity to regulate or vicariously experience of other's emotions, especially when that emotion is directed towards oneself (which was the case with the current couples' interaction task) is critical for intimate relationships. Thus our results are in line with several studies supporting the association between HRV and individual differences in regulated emotional responding (e.g., Appelhans and Luecken 2006; Fabes and Eisenberg 1997), as well as with compassion and empathic concern (e.g., Eisenberg et al. 1996; Porges et al. 1999). Similar results were found in studies that examined self-reported emotion regulation in response to stress in college students (Fabes and Eisenberg 1997) and with children whose HRV has also been associated with emotional regulation and prosocial behaviors (e.g., Fabes et al. 1994).

The present study is not free from limitations. A possible limitation is related with the fact that the positive and negative interactions were not counter balanced, that is, the negative interaction condition always preceded the positive one. As we mentioned in the method, this option, was justified by ethical concerns, but in fact this research design did not allow us to test the possible effect of a down regulation induced by positive emotions that has pointed out by some authors in the literature (e.g. Yuan et al. 2010). Thus when interpreting the decreased levels of heart rate and cortisol in the positive interaction condition when compared with the negative one, we cannot rule out the hypothesis of recovery effect from the negative interaction, coherent with the idea that a possible function of positive emotions is the undoing of physiological arousal produced by negative emotions.

\section{Implications of the Study}

Our findings have important implications for couple's therapy and empathy promotion interventions. Couple's literature shows that the ability to empathize with each other's negative affect is positively associated with relationship satisfaction and negatively associated with interpersonal conflict (Perrone-McGovern et al. 2014). On the other hand, more empathic individuals are those who are able to regulate their own emotional reactions and physiological arousal even in situations of conflict in which they are the object of hostility or anger (Eisenberg et al. 2004; Hein and Singer 2008).

Our results showing that negative interactions were associated with higher cardiac arousal and cortisol levels may help us understand why it is so difficult for couples to maintain an empathic stance in situations of open conflict. This may be instrumental for devising therapeutic interventions helping with the regulation of physiological arousal. This can be done either through cognitive therapy that helps partners de-escalate during conflict or by redirecting couples to express vulnerability rather than anger for example. Those interventions can also take the form of relaxation techniques or biofeedback training or neuromodulation techniques applied during therapy sessions or at home providing real-time feedback to the subject on his/her physiological responding as it occurs in natural contexts. 
Therefore and altough our sample is composed by non distressed couples, our results are even more relevant for distressed relationships in which negative affect is repeatedly elicited. On the other hand, our results help us understand the cumulative effects of negative interactions for the spouses' physical health. As documented by the literature, being in a distressed marriage is a risk factor for negative health outcomes, including heart disease and cancer (Burman and Margolin 1992; Robles and Kiecolt-Glaser 2003), which may be explained by the repeated and chronic activation of the SNS or HPA axis (Repetti et al. 2009) that distressed couples experience on a daily basis. Future studies should try to replicate these results with a sample of couples who are experiencing marital violence and severe conflict for whom the effects of autonomic arousal and stress-reated hormones becomes repeated, chronic and long lasting. We believe that the present study provided a template for applying psychophysiological methods in marital and family interactions.

Funding This study was funded by BIAL Foundation (Grant number: 87/12). Joana Coutinho was funded by a FCT postdoctoral grant (No. SFRH/BPD/75014/2010). This study was conducted at Psychology Research Centre (UID/PSI/01662/2013), University of Minho, and supported by the Portuguese Foundation for Science and Technology and the Portuguese Ministry of Education and Science through national funds and co-financed by FEDER through COMPETE2020 under the PT2020 Partnership Agreement (POCI-01-0145-FEDER-007653).

\section{Compliance with Ethical Standards}

Conflict of interest The authors declare that they have no conflict of interest.

Research Involving with Human and Animal Participants This study involved human participants. All the procedures performed were in accordance with the ethical standards of the institutional and/ or national research committee and with the 1964 Helsinki declaration and its later amendments or comparable ethical standards.

Informed Consent Informed consent was obtained from all individual participants included in the study.

\section{References}

Andreassi, J. (2007). Heart activity and behavior. II. Stress, emotions, motivation, personality, social factors, brain interactions, and conditioning. Psychophysiology: Human behavior and physiological response (5th edn). Mahwal, NJ: Lawrence Erlbaum Associates, Inc., Publishers.

Appelhans, B. M., \& Luecken, L. J. (2006). Heart rate variability as an index of regulated emotional responding. Review of General Psychology, 10(3), 229.

Berntson, G. G., Quigley, K. S., \& Lozano, D. (2007). Cardiovascular psychophysiology. Handbook of Psychophysiology, 3, 182-210.

Billman, G. E. (2011). Heart rate variability-a historical perspective. Frontiers in Physiology, 2, 86.
Bookwala, J. (2005). The role of marital quality in physical health during the mature years. Journal of Aging and Health, 17(1), 85-104.

Bradley, M. M., Codispoti, M., Cuthbert, B. N., \& Lang, P. J. (2001). Emotion and motivation I: Defensive and appetitive reactions in picture processing. Emotion (Washington, D. C.), 1(3), 276.

Broadwell, S. D., \& Light, K. C. (1999). Family support and cardiovascular responses in married couples during conflict and other interactions. International Journal of Behavioral Medicine, 6(1), 40-63.

Burman, B., \& Margolin, G. (1992). Analysis of the association between marital relationships and health problems: an interactional perspective. Psychological Bulletin, 112(1), 39.

Busby, D. M., Christensen, C., Crane, D. R., \& Larson, J. H. (1995). A revision of the Dyadic Adjustment Scale for use with distressed and nondistressed couples: Construct hierarchy and multidimensional scales. Journal of Marital and family Therapy, 21(3), 289-308.

Cacioppo, J. T., Berntson, G. G., Larsen, J. T., Poehlmann, K. M., \& Ito, T. A. (2000). The psychophysiology of emotion. Handbook of Emotions, 2, 173-191.

Cacioppo, J. T., Tassinary, L. G., \& Berntson, G. (2007). Handbook of psychophysiology. Cambridge, NY: Cambridge University Press.

Camm, A. J., Malik, M., Bigger, J. T., Breithardt, G., Cerutti, S., Cohen, R. J., ... Lombardi, F. (1996). Heart rate variability: Standards of measurement, physiological interpretation and clinical use. Task Force of the European Society of Cardiology and the North American Society of Pacing and Electrophysiology. Circulation, 93(5), 1043-1065.

Carvalho, S., Leite, J., Galdo-Álvarez, S., \& Gonçalves, Ó. F. (2012). The emotional movie database (EMDB): A self-report and psychophysiological study. Applied Psychophysiology and Biofeedback, 37(4), 279-294.

Christensen, A., Atkins, D. C., Berns, S., Wheeler, J., Baucom, D. H., \& Simpson, L. E. (2004). Traditional versus integrative behavioral couple therapy for significantly and chronically distressed married couples. Journal of Consulting and Clinical Psychology, 72(2), 176.

Codispoti, M., Surcinelli, P., \& Baldaro, B. (2008). Watching emotional movies: Affective reactions and gender differences. International Journal of Psychophysiology, 69(2), 90-95.

Costa, M. D., Davis, R. B., \& Goldberger, A. L. (2017). Heart rate fragmentation: A new approach to the analysis of cardiac interbeat interval dynamics. Frontiers in Physiology, 8, 255.

Coutinho, J., Beiramar, A., Silva, C., Lema, A., Lima, V., Grace, R., ... Sampaio, A. (2015). Evidências de validade da versão portuguesa do Índice de Reatividade Interpessoal para Casais. Avaliação Psicológica, 14(3).

Coyne, J. C., Rohrbaugh, M. J., Shoham, V., Sonnega, J. S., Nicklas, J. M., \& Cranford, J. A. (2001). Prognostic importance of marital quality for survival of congestive heart failure. The American Journal of Cardiology, 88(5), 526-529.

Cuthbert, B. N., Schupp, H. T., Bradley, M. M., Birbaumer, N., \& Lang, P. J. (2000). Brain potentials in affective picture processing: covariation with autonomic arousal and affective report. Biological Psychology, 52(2), 95-111.

Davis, M. H. (1980). A multidimensional approach to individual differences in empathy. JSAS Catalog of Selected Documents in Psychology, 10, 85.

Eisenberg, N., Fabes, R. A., Murphy, B., Karbon, M., Smith, M., \& Maszk, P. (1996). The relations of children's dispositional empathy-related responding to their emotionality, regulation, and social functioning. Developmental Psychology, 32(2), 195.

Eisenberg, N., Valiente, C., \& Champion, C. (2004). Empathy-related responding: Moral, social, and socialization correlates. The Social Psychology of Good and Evil, 4, 386-415. 
Ekman, P., Levenson, R. W., \& Friesen, W. V. (1983). Autonomic nervous system activity distinguishes among emotions. Science, 221(4616), 1208-1210.

El-Sheikh, M., Kouros, C. D., Erath, S., Cummings, E. M., Keller, P., \& Staton, L. (2009). Marital conflict and children's externalizing behavior: Pathways involving interactions between parasympathetic and sympathetic nervous system activity. Monographs of the Society for research in Child Development, 74(1), vii.

Erickson, K., Drevets, W., \& Schulkin, J. (2003). Glucocorticoid regulation of diverse cognitive functions in normal and pathological emotional states. Neuroscience and Biobehavioral Reviews, 27(3), 233-246.

Fabes, R. A., \& Eisenberg, N. (1997). Regulatory control and adults' stress-related responses to daily life events. Journal of Personality and Social Psychology, 73(5), 1107.

Fabes, R. A., Eisenberg, N., Karbon, M., Troyer, D., \& Switzer, G. (1994). The relations of children's emotion regulation to their vicarious emotional responses and comforting behaviors. Child development, 65(6), 1678-1693.

Feinberg, M. E., Jones, D. E., Granger, D. A., \& Bontempo, D. E. (2013). Anxiety and chronic couple relationship stress moderate adrenocortical response to couple interaction in expectant parents. British Journal of Psychology, 104(4), 525-542.

Gallo, L. C., Troxel, W. M., Matthews, K. A., \& Kuller, L. H. (2003). Marital status and quality in middle-aged women: Associations with levels and trajectories of cardiovascular risk factors. Health Psychology, 22(5), 453.

Gottman, J. M. (1994). An agenda for marital therapy. In The heart of the matter: Perspectives on emotion in marital therapy, pp. 256-293.

Greenwald, M. K., Cook, E. W., \& Lang, P. J. (1989). Affective judgment and psychophysiological response: Dimensional covariation in the evaluation of pictorial stimuli. Journal of Psychophysiology, 3(1), 51-64.

Hein, G., \& Singer, T. (2008). I feel how you feel but not always: The empathic brain and its modulation. Current Opinion in Neurobiology, 18(2), 153-158.

Hugdahl, K. (1995). Psychophysiology: The mind-body perspective. Harvard University Press.

Jennings, J. R., Kamarck, T., Stewart, C., Eddy, M., \& Johnson, P. (1992). Alternate cardiovascular baseline assessment techniques: Vanilla or resting baseline. Psychophysiology, 29(6), $742-750$

Kiecolt-Glaser, J. K., Glaser, R., Cacioppo, J. T., MacCallum, R. C., Snydersmith, M., Kim, C., \& Malarkey, W. B. (1997). Marital conflict in older adults: Endocrinological and immunological correlates. Psychosomatic Medicine, 59(4), 339-349.

Kiecolt-Glaser, J. K., \& Newton, T. L. (2001). Marriage and health: His and hers. Psychological Bulletin, 127(4), 472.

Kok, B. E., \& Fredrickson, B. L. (2010). Upward spirals of the heart: Autonomic flexibility, as indexed by vagal tone, reciprocally and prospectively predicts positive emotions and social connectedness. Biological Psychology, 85(3), 432-436.

Kreibig, S. D. (2010). Autonomic nervous system activity in emotion: A review. Biological Psychology, 84(3), 394-421.

Lang, P. J., Bradley, M. M., \& Cuthbert, B. N. (2008). International affective picture system (IAPS): Affective ratings of pictures and instruction manual. Technical report A-8.

Lang, P. J., Greenwald, M. K., Bradley, M. M., \& Hamm, A. O. (1993). Looking at pictures: Affective, facial, visceral, and behavioral reactions. Psychophysiology, 30(3), 261-273.

Lehnart, J., Neyer, F. J., \& Eccles, J. (2010). Long-term effects of social investment: The case of partnering in young adulthood. Journal of Personality, 78(2), 639-670.

Levenson, R. W. (2003). Blood, sweat, and fears. Annals of the New York Academy of Sciences, 1000(1), 348-366.
Levenson, R. W., \& Gottman, J. M. (1985). Physiological and affective predictors of change in relationship satisfaction. Journal of Personality and Social Psychology, 49(1), 85.

Limpo, T., Alves, R. A., \& Catro, S. L. (2010). Medir a empatia: adaptação portuguesa do Índice de Reactividade Interpessoal. Laboratório de Psicologia, ISPA, 8(2), 171-184.

Markman, H. J. (1981). Prediction of marital distress: A 5-year followup. Journal of Consulting and Clinical Psychology, 49(5), 760.

Matthews, K. A., \& Gump, B. B. (2002). Chronic work stress and marital dissolution increase risk of posttrial mortality in men from the Multiple Risk Factor Intervention Trial. Archives of Internal Medicine, 162(3), 309-315.

Mayne, T. J., O'leary, A., McCrady, B., Contrada, R., \& Labouvie, E. (1997). The differential effects of acute marital distress on emotional, physiological and immune functions in maritally distressed men and women. Psychology and Health, 12(2), 277-288.

Nealey-Moore, J. B., Smith, T. W., Uchino, B. N., Hawkins, M. W., \& Olson-Cerny, C. (2007). Cardiovascular reactivity during positive and negative marital interactions. Journal of Behavioral Medicine, 30(6), 505-519.

Newton, T. L., \& Sanford, J. M. (2003). Conflict structure moderates associations between cardiovascular reactivity and negative marital interaction. Health Psychology, 22(3), 270.

Notarius, C. I., \& Levenson, R. W. (1979). Expressive tendencies and physiological response to stress. Journal of Personality and Social Psychology, 37(7), 1204.

Orth-Gomer, K., Wamala, S. P., Horsten, M., Schenck-Gustafsson, K., Schneiderman, N., \& Mittleman, M. A. (2000). Marital stress worsens prognosis in women with coronary heart disease: The Stockholm Female Coronary Risk Study. JAMA: The Journal of the American Medical Association, 284(23), 3008-3014.

Perrone-McGovern, K. M., Oliveira-Silva, P., Simon-Dack, S., Lefdahl-Davis, E., Adams, D., McConnell, J., ... Gonçalves, Ó. F. (2014). Effects of empathy and conflict resolution strategies on psychophysiological arousal and satisfaction in romantic relationships. Applied Psychophysiology and Biofeedback, 39(1), 19-25.

Péloquin, K., \& Lafontaine, M. F. (2010). Measuring empathy in couples: Validity and reliability of the interpersonal reactivity index for couples. Journal of Personality Assessment, 92(2), 146-157.

Pereira, M. G. (2003). Revised dyadic adjustment scale - Versão de investigação. Manuscrito não publicado, Universidade do Minho, Braga, Portugal.

Porges, S. W. (2007). The polyvagal perspective. Biological Psychology, 74(2), 116-143.

Porges, S. W. (2009). The polyvagal theory: New insights into adaptive reactions of the autonomic nervous system. Cleveland Clinic Journal of Medicine, 76(Suppl 2), S86.

Porges, S. W., Doussard-Roosevelt, J. A., Stifter, C. A., McClenny, B. D., \& Riniolo, T. C. (1999). Sleep state and vagal regulation of heart period patterns in the human newborn: An extension of the polyvagal theory. Psychophysiology, 36(01), 14-21.

Repetti, R., Wang, S. W., \& Saxbe, D. (2009). Bringing it all back home: How outside stressors shape families' everyday lives. Current Directions in Psychological Science, 18(2), 106-111.

Robles, T. F., \& Kiecolt-Glaser, J. K. (2003). The physiology of marriage: Pathways to health. Physiology and Behavior, 79(3), 409-416.

Robles, T. F., Shaffer, V. A., Malarkey, W. B., \& Kiecolt-Glaser, J. K. (2006). Positive behaviors during marital conflict: Influences on stress hormones. Journal of Social and Personal Relationships, 23(2), 305-325.

Rodriguez, A. J., \& Margolin, G. (2013). Wives' and husbands' cortisol reactivity to proximal and distal dimensions of couple conflict. Family Process, 52(3), 555-569.

Sánchez-Navarro, J. P., Martínez-Selva, J. M., Román, F., \& Torrente, G. (2006). The effect of content and physical properties of 
affective pictures on emotional responses. The Spanish Journal of Psychology, 9(02), 145-153.

Schwabe, L., Haddad, L., \& Schachinger, H. (2008). HPA axis activation by a socially evaluated cold-pressor test. Psychoneuroendocrinology, 33(6), 890-895.

Smith, A. L., Ullrich-French, S., Walker, E., \& Hurley, K. S. (2006). Peer relationship profiles and motivation in youth sport. Journal of Sport and Exercise Psychology, 28(3), 362.

Spanier, G. B. (1976). Measuring dyadic adjustment: New scales for assessing quality of marriage and similar dyads. Journal of Marriage and the Family, 38(1), 15-28.

Stemmler, G. (2003). Methodological considerations in the psychophysiological study of emotion. Handbook of Affective Sciences, 17, 225-255.

SunWoo, K., \& Marks, N. F. (2016). Marital strain exacerbates health risks of filial caregiving: Evidence from the 2005 National Survey of Midlife in the United States. Journal of Family Issues, 37(8), $1123-1150$.

Thayer, J. F., Åhs, F., Fredrikson, M., Sollers, J. J., \& Wager, T. D. (2012). A meta-analysis of heart rate variability and neuroimaging studies: Implications for heart rate variability as a marker of stress and health. Neuroscience and Biobehavioral Reviews, $36(2), 747-756$.
Thayer, J. F., \& Lane, R. D. (2000). A model of neurovisceral integration in emotion regulation and dysregulation. Journal of Affective Disorders, 61(3), 201-216.

Tomaka, J., Blascovich, J., Kelsey, R. M., \& Leitten, C. L. (1993). Subjective, physiological, and behavioral effects of threat and challenge appraisal. Journal of Personality and Social Psychology, 65(2), 248.

Trimmel, K., Sacha, J., \& Huikuri, H. V. (Eds.) (2015). Heart rate variability: Clinical applications and interaction between HRV and heart rate. Lausanne: Frontiers Media SA.

Umberson, D., Williams, K., Powers, D. A., Liu, H., \& Needham, B. (2006). You make me sick: Marital quality and health over the life course. Journal of Health and Social Behavior, 47(1), 1-16.

Weinberger, D. A., Schwartz, G. E., \& Davidson, R. J. (1979). Lowanxious, high-anxious, and repressive coping styles: Psychometric patterns and behavioral and physiological responses to stress. Journal of Abnormal Psychology, 88(4), 369.

Yuan, J. W., McCarthy, M., Holley, S. R., \& Levenson, R. W. (2010). Physiological down-regulation and positive emotion in marital interaction. Emotion (Washington, D. C.), 10(4), 467-474. 